\title{
Stumped by Headlines: Investigating a Functional Knowledge Deficit ${ }^{*}$
}

\section{SHELDON UNGAR}

University of Toronto at Scarborough

\begin{abstract}
Competing claims about the level of ignorance, or knowledge, among the current Nexus generation are addressed. The core of the paper is a theoretical analysis of ignorance in the knowledge society. Specifically, the knowledge-ignorance paradox suggests that the intense specialization demanded by a knowledge economy militates against a broader information society and gives rise to "reading reluctance." To provide evidence for this analysis, the results of a small-scale study testing the idea of a "functional knowledge deficit" are presented. Students were asked to identify metaphorical terms that are commonly used without definition in newspaper captions. The results revealed that students could only identify about $30 \%$ of these common expressions, and that they did not do better with terms derived from computers or the popular culture. Significant differences were also found between male and female responses. Both the implications of the findings and further avenues of research are discussed.
\end{abstract}

* The author would like to thank Malcolm Mackinnon for helpful comments on an earlier version of this paper. This research was supported by a grant from the Social Science and Humanities Research Council of Canada. "Icons and Gumpism: Studies in the Production of Ignorance in the "Information Society." 


\section{RÉSUMÉ}

Cet article discute des débats tenus au sujet du niveau d'ignorance, ou de connaissance, parmi la génération Nexus actuelle. Le coeur de l'article est une analyse théorique de l'ignorance dans la société du savoir. Particulièrement, le paradoxe connaissance-ignorance suggère que l'intense spécialisation requise par une économie du savoir milite contre une société de l'information plus avertie et donne naissance à une "répugnance de la lecture." Comme preuve à l'appui de cette analyse, les résultats d'une étude à petite échelle vérifiant la notion de "déficience de connaissance fonctionnelle" sont présentés. On a demandé à des étudiants d'identifier les métaphores utilisées couramment sans définition dans les sous-titres de journaux. Les résultats ont révélé que les étudiants pouvaient seulement identifier envion $30 \%$ de ces expressions courantes et qu'ils ne s'en étaient guère mieux tirés avec les termes dérivés de l'informatique ou de la culture populaire. On a également trouvé des différences significatives entre les résponses des deux sexes. Les répercussions de ces résultats ainsi que d'autres débouchés de recherche sont discutés.

\section{INTRODUCTION}

In a recent Toronto Star article, 22 faculty claimed that student "vocabularies are more limited, as is their knowledge of history. They lack the habit and the love of reading good books" (Pangle, 1996). I share their concern. With 15 years experience teaching introductory Sociology, I have been forced to admit that the only information most of us share in common comes from television. In trying to explain the arbitrary nature of social order, I do not draw on Robinson Crusoe. Mention Crusoe and you get too many puzzled looks. So I introduce the ideas by way of Gilligan's Island. It resonates.

In contrast to faculty hand-wringing, others assert that the young are "the most well-informed generation to date" (Barnard, Cosgrave, \& Welsh, 1998, p. 30). From this point of view, the current "Nexus generation" was raised in an education system that favoured critical reasoning and problem-solving over rote learning. The name of the game is to 
dissect and reassemble concepts, not just memorize them. What this generation does not know factually, it makes up for by honing its analytic skills. The young are media literate and ostensibly draw on several sources so they can get the facts right.

To adjudicate between these opposing claims, it is first necessary to develop a systematic sociological account of the emerging information environment, and not just look at individual phenomena like television. After elaborating on claims made about youth ignorance, an overview of the knowledge-ignorance paradox is presented (Ungar, 1999, 2000a, $2000 \mathrm{~b}$ ). The articulation of this paradox suggests that the intense specialization and informational pressures demanded by a knowledge economy lead to both an increase in general ignorance as well as a degree of informational reactance (Royce, 1997).

Beyond theorizing, there is a need to study systematically what the young know, as well what they don't know. Hence, the paper develops a revised version of the methods employed by Hirsch and colleagues (1987) to test for the existence of a "functional knowledge deficit." Specifically, it identifies metaphorical terms that are commonly used without definition in newspaper captions. The results of a preliminary investigation of student recognition of metaphorical terms are presented in this article.

\section{CLAIMS ABOUT THE PROBLEM OF YOUTH IGNORANCE}

A letter to editor in the December 1999 issue of Harper's suggests that, "These days you can't swing a dead cat without hitting some academic lamenting American youths' inability to appreciate literature..." J.M. Coetzee (1999), American professor and award winning South African novelist writes, "He had long ceased to be surprised at the range of ignorance of his students. Post-Christian, post-historical, postliterate, they might as well be hatched from eggs yesterday" (p. 32). While such examples can be multiplied almost endlessly (Bercuson, Bothwell, \& Granatstein, 1997), they remain anecdotal and are plagued by interpretive problems.

The youth decline argument is old hat. As Gabler (1998) observes, every generation since about the time of Plato seems to believe that its 
progeny are the barbarians at the gates. Still, he claims that a decline in intellectual capital has occurred since the mid-1800s:

Literacy among ordinary Americans was relatively high then, and nearly everyone seemed to love to read... Most ordinary citizens were familiar with opera and Shakespeare. These same folks would sit for hours listening to political debate... (p. 29)

This argument, however, raises a host of difficulties that bring us to the heart of our concern with the information society.

The first difficulty here is (as one might expect) the paucity of evidence presented about ostensibly ordinary folks in the past. More generally, systematic longitudinal evidence on ignorance among the young is either nonexistent or highly problematic (Miller \& Goyder, 2000). ${ }^{1}$ Second, Gabler falls into the trap of comparing illiteracies, declaring that my (high!) culture is better than yours. This stance amounts to a Beethoven bests the Beatles contention, with the further stipulation that my culture is good for you even if you don't like it (see Cowen, 1998). Missing from this analysis is a realization that the relevance of different types of knowledge can change over time, and the young may not be more ignorant so much as know different things (Barnard et al., 1998). While it is easy to adopt a sneering attitude of cultural superiority, knowledge can be rendered obsolete: the educated no longer learn Latin, and user-friendly computer programs have obviated the need to learn Fortran.

Finally, we come to the most fundamental problem. While it is natural to draw comparisons with the past, the idea of an information society is relatively new. For example, neither "information" nor "communication" made the list of 102 "great ideas" used to organize the Great Books of the Western World, published by Encyclopedia Britannica in 1952. Indeed, it was not until the early 1960 s that the numerous attempts to capture the ongoing major transformation of industrial societies began to draw on the idea of information (Beniger, 1986). Given its recent pedigree, it is probably not sufficient to assert that the young don't know less than they knew in the past. If the presumptions surrounding the "information" revolution have merit, then questions about the amount of and demands for knowledge, as well as exposure and access to it need to be reconsidered. ${ }^{2}$ So important is this comparison issue that an illustrative (military) example is called for. 
During World War One, once a battle was joined:

Generals were like men without eyes, without ears and without voices, unable to watch the operations they set in progress, unable to hear reports of their development and unable to speak to those whom they had originally given orders... (Keegan, 1998, p. 321).

Communication was based on a grid of inflexible telephone cables, which were repeatedly cut by artillery fire and could not be laid quickly enough to keep up with advancing troops. Information arrived fitfully and was always woefully incomplete; underload, in 1914, consumed time as commanders puzzled through a "fog of war." Breakthroughs required pauses, as the communication of information and the issuing of new orders took about six hours (Keegan, 1998).

Modern communications systems used in the Gulf War allow surveillance, targeting and intercommunication in "real time" (Owens, 2000). Instant word-of-mouth communication and the simultaneous observation of events in "virtual reality" consume time by threatening overload. The implication - and this is not limited to the military - is that there is limited value in trying to draw parallels between the information demands of the past and those of the present. ${ }^{3}$

\section{THE KNOWLEDGE.IGNORANCE PARADOX}

The idea that we are living in an increasingly information-based society is largely taken for granted in public discourse (Martin, 1995). That the term is a gloss is clearly recognized by Drucker (1993): "It may be premature (and certainly would be presumptuous) to call ours a "knowledge society;' so far, we have only a knowledge economy" (p. 30). Certainly there has been a rapid proliferation of scientific and technical knowledge, as well as other forms of data and information. ${ }^{4}$ But most of this data is used by experts or teams of experts involved in specialized occupational roles. Beyond specialized knowledge as an economic factor, elements of an information society are reflected in the multifold advances in the technology for storing, accessing and distributing information. 
Both the Internet and the impending world of 500 television channels afford abundant informational opportunities.

That information, regardless of how it is defined in a technical sense, is exploding is incontestable. There is also an indubitable underside to this tidal wave of information - a general increase in ignorance among members of society. Ungar (1999, 2000a, 2000b) employs the notion of a "knowledge-ignorance paradox" (KIP) to capture how the growth of specialized knowledges implies a simultaneous increase in ignorance. Lukasiewicz (1994) observes that exponential growth in the volume and complexity of information creates the prospect of "instant antiquity." In addition, one's degree of grasp (the ratio of information the human intellect can handle to the volume of information available) "is quickly diminishing while one's [degree of] ignorance is on a fast rise" (p. 122).

The starting point for grasping the specialized KIP is the proliferation of knowledge at work. So great has been this proliferation that typologies of "information occupations" are so extensive as to be uninformative (Martin, 1995). There has also been a "technization" of work, whereby computerization leads to increased emphasis on the creation and manipulation of symbols (Barley \& Orr, 1997). As information pervades the economy, many specialty domains face an exponential growth in the volume and complexity of information.

Role incumbents in specialized knowledge domains may well feel besieged, although the extent depends on the strategies used to manage information pressures. Despite expectations that experts should "keep up," a poll of family physicians revealed that $64 \%$ did not know that the symptoms of heart disease differ in women and men (Ungar, 1999). Rather than falling behind, a more general strategy is to increasingly constrict defined areas of specialization. What was noted about physics in the $1940 \mathrm{~s}$ - professional talk could not be conducted with colleagues in adjacent offices — now extends to many other realms of knowledge.

This brings us to a key hypothesis. Specifically, the specialized KIP predicts an overall decline in the stock of general or common knowledge. Besides the specialization pressures that can besiege occupational role incumbents, increases in the volume and complexity of information escalate the entry costs to virtually every other knowledge domain. 
Research on the knowledge gap hypothesis reveals that prior knowledge in an area is critical in order to assimilate new information in that area (Viswanath \& Finnegan, 1996). Starting with conceptual anchors, the gaining of knowledge in a field tends to follow a spiral model, with new bits added to prior accumulations. But as proliferating conceptual anchors and technical terms (or what librarians call "twiggings") are overlaid with new facts and frequent revisions, specialty knowledge domains become forbidding to outsiders. All but the most persistent nonspecialists are effectively precluded from keeping up.

\section{IDENTIFYING FUNCTIONAL KNOWLEDGE DEFICITS}

Overall then, the specialty KIP fosters narrowly constituted communities of experts whose arcane bubbles of shared knowledge overlap minimally with other bubbles. Between exploding informational demands at work and the attendant heightening of entry barriers to other domains of information, acquiring knowledge outside of work not only presents many obstacles, but also invokes a degree of reactance. Since many experts are being compelled to rely on pre-digested knowledge packages in their own specialties, one can hardly expect them to be knowledge seeking in a wide range of other domains (Ross, 1994; Ungar, 2000a). In this regard, evidence of reactance comes from research by Royce (1997) showing that information overload can lead to "reading reluctance."

Ultimately, the KIP renders spaces of ignorance pervasive and thereby undermines the idea of a knowledge society (see Lane, 1966). For present purposes, the threat that the specialized KIP may harrow the stock of common social knowledge is most salient. On the one hand, students face intense competition for grades and other job-related skills in an educational context that increasingly demands "information literacy," i.e., the capacity to seek and find information (Breivik, 1998). On the other hand, the counterpart to these demands for specialized knowledge is an institutional context and popular culture that appear to devalue cultural literacy or intellectual capital and uphold a downward leveling of ideas and conversation. ${ }^{3}$ In this regard, Bibby (2001) reports that only $16 \%$ of 
national sample of teens claim to keep up with the news as a daily activity; $92 \%$ watch TV on a daily basis (p. 28).

Efforts to investigate purported declines in common or general knowledge are beset by a host of problems. For reasons seldom or poorly stated, researchers tend to focus on aristocracies of knowledge science and history for example - but not popular culture. Surveys of the public on these subjects employ preordained yardsticks. That is, investigators stipulate in advance what people should know, but typically fail to provide sufficient justification for their choices. This "epistemological conceit," as Reser and Smithson (1988-89, p. 13) term it, is illustrated in the research on political knowledge, where it is common to ask questions about topics like the names of local politicians. People do poorly here, but it is not clear why they should know these names. This type of information is hardly edifying as such, being mostly useful when one needs to contact local politicians. In this case, finding their names is the issue, pointing to a difference between what one knows and one's capacity to find information (i.e., information literacy) as the need arises.

The one systematic attempt "to identify and define the knowledge assumed in public discourse" is by Hirsch (1987) (see also, Hirsch, Kett, \& Trefil, 1993). To locate items that ought to be known "by a broad majority of literate Americans," Hirsch et al. (1993, p. ix) drew on a "wide range of national periodicals" and selected entries that "refer to an event, person or thing without defining it." But the upshot of this selection procedure is a dictionary of cultural literacy that is immeasurably larger, more inclusive and wider ranging than can be supported by the results obtained in the research on what the public knows (Bart \& EvansStout, 1997). The apparent error that leads Hirsch to mis-specify the realm of cultural literacy is that the readers of (mostly specialty) periodicals are self-selected and hence writers and editors can assume specific knowledge due to the distinctive nature of their readership. When these atypical selections are amalgamated across a wide range of periodicals, the resultant listing is unrealistic and prescriptive rather than descriptive. In this regard, consider the "everyone" invoked in this quotation: "Everyone knows about the Wannsee Conference and most are aware of 
the link between Hitler's eugenic views and the science of the time" (Jones, 1993, p. 33).

To avoid these problems, the present study examines what can be termed functional knowledge deficits. Research reveals high levels of public ignorance concerning mutual fund risks (about $50 \%$ of Canadians surveyed believe they are covered by the Deposit Insurance Fund), women's heart disease, understanding and heeding medical instructions, as well as many of the effects of smoking and the risks of sexually transmitted diseases (Dente, 2000; Ungar, 2000a). These informational deficits amount to more than asserting that my version of cultural literacy trumps yours. Rather, ignorance in these realms suggests that people lack the facts and/or analytic tools to deal with important social, citizenship, and personal or practical issues.

Since there are many realms of functional knowledge - ranging from consumer decisions to health to investment planning through local environmental, social and political concerns - this study operationalizes functional knowledge by examining student recognition of common terms or expressions found in the captions of newspaper articles. Effectively, the use of terms found only in headlines allows us to employ a satisfactory facsimile of Hirsch's methodology while avoiding the amalgamation problem discussed above. For the most part, "metaphorical terms" have been selected, i.e., expressions that are widely utilized, often applied symbolically (Trojan horse is rendered as "Trojan gene" and "Trojan virus" in the case of HIV), and typically used without definition. In other words, they are terms that often have multiple associations and, by implication, are deemed to be part of the operating stock of common knowledge. According to Dijk (1988), headlines serve as retrieval cues to activate the relevant regimes of truth that make public knowledge possible. By their very appearance as "hooks" in the headlines of mass circulation newspapers then, these terms are taken for granted as part of the bedrock of public discourse. The use of such terms obviates the problems associated with selecting "facts" that people ought to know, and comes closer to tapping into the analytic tools they possess (see Barnard et al., 1998). 
Based on the knowledge gap hypothesis, it follows that an inability to understand terms used in captions will lessen the chance of the article being read, much less understood. The headlines become obstacles to understanding rather than facilitators of interest and knowledge, which is what they are intended to be. If phrases like "Police Gestapo Tactics," the "Silicon Valley of the North," a "Marshall Plan for Africa," or "No Magic Bullet for AIDS" are meaningless, it suggests that people do not possess the conceptual anchors needed to deal effectively with particular realms of citizenship or practical knowledge. In this vein, both social and intellectual capital are positively associated with civic and political participation (Paxton, 1999).

\section{METHODS}

Respondents were a convenience sample of 147 students in an Introduction to Sociology course at the University of Toronto at Scarborough who voluntarily completed a questionnaire on "Identifying Common Terms" (five students chose not to participate). There were 95 females and 52 males in the sample. A gender ratio favouring females is common in sociology courses. Demand for these courses exceeded available places, and since the computer system used for registration gives preference to first year students over those in later years, virtually all students would have been in first year.

Results were collected in the second week of classes, so they effectively measure what students knew in leaving high school and are not confounded by University effects. Questionnaire instructions were as follows:

This study seeks to determine what terms or phrases newspapers and TV can use without defining them. For each term below, please indicate those you know with a relevant phrase or two (such as what they mean or how they are used). No one is expected to know all the terms. Indeed, it is not a problem if you cannot identify many of them - these may be terms that are simply not in common use.

Several examples of how to identify terms were shown to the class. Respondents were then given 30 minutes to complete the questionnaire. ${ }^{6}$

The selection of metaphorical terms was made from the Toronto Star, the Toronto Sun, and Whitby this Week, a suburban community 
newspaper published tri-weekly. None of these sources assumes a specialty audience; each is purposively targeted to a broad or mass audience whose literacy level falls well below that presumed at university.

A number of factors dictated the choice of terms. First, selected terms had to appear in captions in at least two of the three sources under study. These newspapers were perused for eligible content during the 1998-99 academic year. Second, terms were selected to cover a wide range of topics - political, military, medical, economic, computer, and popular culture. Preference was given to those terms with metaphorical associations, such as Blitzkrieg, Kafkaesque, Placebo and Harvard. Finally, since preliminary research revealed that students become discouraged at the task if all the terms are unfamiliar, the questionnaire included terms that were seemingly so commonplace that they could be counted as "filler" that any student would know.

A research assistant coded responses as either correct or incorrect (a third category used for some terms is discussed below). To avoid overstating the level of ignorance, responses were coded as correct if they displayed any familiarity with the term. For example, an "investment" or "a stock" was counted as correct for RRSP. Saying "our generation" for Generation X was also accepted. Sputnik was counted as an "American spaceship," and Antibiotic resistance was extended to "viruses" as well. "Something to do with computers" sufficed for RAM. Effectively, any link to the metaphorical term that was at least partially correct was accepted. Since students have to fill in their own responses, many incorrect responses were of course blanks. However, being "mentally exhausted" did not count for Brain drain.

A reliability check with a random selection of 20 questionnaires coded by the author revealed over $95 \%$ agreement in coding. Two questionnaires were employed, the second inverting the order of terms found in the first. A comparison of responses over the two questionnaires revealed no significant differences, and hence the ordering of items is ignored in the ensuing analysis. 


\section{RESULTS}

Table 1 presents an ordered listing of correct responses based on percentages arrayed by decile. The percent at the top of each decile represents the highest percent correct responses in that decile. Overall, the results indicate that students are unfamiliar with these common expressions from newspaper captions. Of the 66 terms listed, students correctly recognized an average of 20.5 , or $31 \%$. Furthermore, of the six terms that were deemed to be filler - Harvard, Bottom line, Woodstock, Wall Street, Alcatraz, and Red neck - five were recognized by $70 \%$ or more of respondents. (The low rate of recognition of Red neck is a bit puzzling, since it appears in jokes and movies.) Omitting these filler terms, if only for the sake of argument, brings the recognition level down to $27 \%$. Only 14 terms were recognized by at least 50 percent of students (i.e., $21 \%$ of terms); this is reduced to nine terms (15\%) if the fillers are removed.

Perusal of responses by type or category of term yields some surprising results. Among those recognized by $50 \%$ or more, there is no clear pattern, though at least five of the expressions have economic associations. However, less than $40 \%$ know of the "Crash of 29" (volatility in the market rendered fear of a crash prevalent in news stories). The remaining terms with economic associations fall below a $20 \%$ recognition level. These include "Brain drain," which has attracted a host of stories over the last few years.

While military terms from the Second World War and the arms race have acquired strong metaphorical resonances, current undergraduates do not grasp the meaning of these terms. More variation is seen in knowledge of political terms, though less than $50 \%$ correctly identify Politically Correct (and even fewer Affirmative Action). The same is true for Chernobyl, while the Challenger accident seems to be fading from view. Scientific and medical terms show large variations, and it is apparent that Ebola has become the disease to fear even though Antibiotic resistance is a more pressing problem.

The defining characteristics of the Nexus generation is having grown up with computers and being immersed in popular culture. If terms from these domains provide a fairer test of their knowledge, the results are 
Table 1

\section{Identification of Metaphorical Terms by Decile}

\begin{tabular}{|c|c|c|}
\hline \multirow{2}{*}{$\begin{array}{l}100 \% \\
\text { Harvard }(95 \%)\end{array}$} & $40 \%$ & $10 \%$ \\
\hline & National Security (39\%)* & Deep Throat (7\% \\
\hline \multirow{4}{*}{$\begin{array}{l}90 \% \\
\text { RRSP }(84 \%) \\
\text { Clone }\end{array}$} & Crash of ' $29^{*}$ & Asian Tigers \\
\hline & Auschwitz & Junk Bonds \\
\hline & Fail Safe & Magic Bullet \\
\hline & Iron Curtain* & McCarthyism \\
\hline \multirow{2}{*}{$\begin{array}{l}\mathbf{8 0} \% \\
\text { Bottom Line }(75 \%)\end{array}$} & Challenger* & Kafkaesque \\
\hline & Silicon Valley* & Lame Duck \\
\hline \multirow{5}{*}{$\begin{array}{l}\text { Ebola } \\
\text { RAM* } \\
\text { Woodstock } \\
\text { Wall Street* } \\
\text { Alcatraz }\end{array}$} & Cyborgs* & New Deal \\
\hline & Trojan Horse & Marshall Plan \\
\hline & D Day* & Orwellian \\
\hline & Virtual Community* & Banana Republic \\
\hline & $30 \%$ & Flame \\
\hline \multirow{3}{*}{$\begin{array}{l}70 \% \\
\text { Bay Street }(69 \%)^{*} \\
\text { Mutual Funds }\end{array}$} & Red Neck $(29 \%)$ & We Have Seen \\
\hline & Affirmative Action & $0 \%$ \\
\hline & Placebo & Zero Sum $(0 \%)$ \\
\hline \multirow{3}{*}{$\begin{array}{l}60 \% \\
\text { Window of } \\
\text { Opportunity }(55 \%)\end{array}$} & Blitzkreig* & MAD \\
\hline & Gestapo & Fifth Column \\
\hline & Global Village & Munich \\
\hline \multirow{2}{*}{$\begin{array}{l}\text { Transparency* } \\
\text { Loose Canon }\end{array}$} & $20 \%$ & \\
\hline & Big Brother $(19 \%)$ & \\
\hline \multirow{5}{*}{$\begin{array}{l}\mathbf{5 0 \%} \\
\text { Guru }(47 \%)^{*} \\
\text { Antiobiotic Resistance } \\
\text { Chernobyl } \\
\text { Generation X }\end{array}$} & Catch 22 & \\
\hline & Pushing the Envelope & \\
\hline & Godot & \\
\hline & Asian Flu & \\
\hline & Double Blind & \\
\hline \multirow{5}{*}{$\begin{array}{l}\text { Sputnik } \\
\text { Politically Correct } \\
\text { Tianiman Square }\end{array}$} & Jihad & \\
\hline & Brain Drain & \\
\hline & Olive Branch & \\
\hline & Ropypnol & \\
\hline & Heroin Chic & \\
\hline
\end{tabular}

* indicates male identification at least $20 \%$ higher than female 
disappointing. While RAM is well known (though still less than $75 \%$ of respondents can identify it), Silicon Valley, Virtual Community, Global Village and Flame all do relatively poorly - or worse, since this is supposed to be the computer generation. Popular Culture fairs no better. Woodstock, which has been commemorated in film, music and riots, is well known; but Cyborgs and Pushing the Envelope are not. Most surprising, Rohypnol (it does no better as "Rophies") is hardly known; yet a drug associated with date rape would seem to be highly relevant. Heroin Chic emerged from the fashion industry and even drew a comment from a U.S. President, but remains unknown.

Finally, we come to what can be called crossover terms. Deep throat, involving a covert informant first associated with Watergate, was barely known at all. However, 13\% of respondents identified the term with a famous porn movie, and informal discussions with students indicate that this usage is actually much better known. Banana Republic as a political designation had no cachet with students. However, $52 \%$ of respondents identified the term with a fashionable clothing designer. This co-optation of the term was unknown to the author at the time the questionnaire was set!

The analysis of gender differences produced puzzling results. Specifically, males identified substantially more items than did females (24.4 vs 18.4). Since this substantial overall difference was not anticipated, gender differences in responses to the individual items were examined. Returning to Table 1, the terms marked with an asterisk are those for which identification by males was at least $20 \%$ higher than identification by females. ${ }^{7}$ Inspection of the results indicates that a number of differences are associated with military metaphors, an area that has conventionally been of greater interest to males than females. But differences are also apparent for economic terms and, most problematic, computer-related ones. A gender gap in computer literacy could have manifold consequences extending into the future.

\section{DISCUSSION}

Respondents in this study could not be accused of having sampled widely from the tree of knowledge. They were stumped by commonplace 
expressions in newspaper headlines - not by the mythological allusions that are part of the conventional conception of cultural literacy. Some prior and common knowledge must be presumed for a speech community to exist. But the current findings attest to a public information void among a sample of undergraduates from a suburban campus of Canada's largest city. That respondents identified less than one third of the metaphorical terms used here is seemingly more than a matter of differences in taste hierarchies. The expressions presented here are meant to tap into a functional knowledge deficit, i.e., an obstacle to the diffusion of information and communication more generally. Trojan horse may be "older" than history, but it has proved to be a durable and robust metaphor. To encounter it and the other terms presented here as unintelligible expressions is to be practically excluded from entry into discourse on significant public issues.

Whereas Barnard et al. (1998) hold that the Nexus generation makes up for its lack of specific factual knowledge with highly honed analytic and conceptual skills, the present results seem to undermine that distinction. Specifically, how does one "dissect and reassemble concepts" that one does not know? Thought and speech cannot be undertaken in a vacuum, and in the absence of common facts, understandings and expressions, individuals are likely to suffer from a fatal disconnectedness. While it might be contended that the expressions used here are not part of the conceptual apparatus central to the Nexus generation, this could be equated with asking for an exemption from public issues and affairs. Moreover, if Silicon Valley, Virtual Community and Cyborgs are unknown by two-thirds of respondents, the claim that they are the "chip" generation rests on what must be very shaky grounds.

Blame for knowledge deficits among the young are variously attributed to, among other things, the school system and the mass media (i.e., Granatstein, 1996). The specialized KIP provides a more socially embedded explanatory approach to the problem, however. It suggests that knowledge explosions impact people most in their occupational roles. Since these explosions are so widespread, there is the additional concomitant of increasing entry barriers to non-work domains, especially as conceptual twiggings render other knowledge domains increasingly 
forbidding. In effect, the knowledge economy militates against a broader knowledge society. Hence, the question arises of whether the KIP - in tandem with the effects of institutions, technology and the popular culture (Ungar, 1999, 2000a) - has sufficiently harrowed the common stock of information that people often do not possess the conceptual tools needed to deal effectively with the realm of citizenship or practical knowledge.

Consider one example of the appropriation of knowledge by technology. As pictured keypads replace numbered ones on cash registers, words, numbers and calculations are transferred from users to machines (Ross, 1994). This imagery may be a boon for the mathematically illiterate, who can always contend that learning math is rote drudgery. However, the capacity to think in a mathematical sense - do size comparisons, grasp the ideas of chance and probability - is not obsolete or redundant.

Pursuant to the line of research undertaken here, there is a need to go beyond sociology students, to strategically compare different campuses, and to employ designs that would uncover university effects (i.e., does knowledge increase or decrease during the time students attend university). Functional knowledge deficits can be tapped in other ways and further specified. Rather than looking at general knowledge, the question of whether people obtain knowledge on a "need-to-know" basis can be investigated. For example, are persons with multiple sex partners more knowledgeable about AIDS and safe sex practices than those with a single partner or who remain celibate?

Finally, there is the question of what students know. If the common stock of knowledge (and especially the ideal of cultural literacy) seems to be withering away, the popular culture may be standing in its stead. As a result of the simultaneous and often symbiotic maturing of a number of technologies - television, video, computers, the Internet - the icons, celebrities, images, and brands that constitute the popular culture are now so prominent and relentless that they can be considered hyper-realities. Research attempting to identify the icons students recognize and to understand their role in conversation is currently underway. 


\section{Notes}

1 Research attempting to determine whether there has been a longterm decline in intercohort verbal ability generates small and inconsistent differences that turn on very complex and controversial causal models. Explanations for possible declines are also hotly contested. The one significant point of agreement is the dumbing down of school textbooks, with pictures often replacing words (Wilson \& Gove, 1999).

2 The next section differentiates between an information economy and the more problematic use of an information or knowledge society. Commentators too often use the latter when they probably are referring to the former. Given this distinction, we follow the lead of Lane (1966) who, in the first systematic sociological account of the concept, employed information society inclusively. No matter what formal definitions are given to the information society, those using it as a master metaphor are not constrained in practice by its narrower economic connotations, but extend it to politics, health, and so on. The narrower meaning has also been considerable broadened by analyses of the impact of the Internet on society. Webster's (1995) concept of the "informatization of life" captures the broader meaning under discussion.

3 Beyond this example, consider how an ordinary person would research treatments for a medical problem in the 1970 s or 80 s as compared to today. Stacked up against medical journals and textbooks, the Internet affords a huge range of up-to-date information, reliable or not, that includes people in experimental drug trials contacting one another and determining who is on placebos and what the side effects of the drugs are (Epstein, 1996).

4 Researchers try to maintain a distinction between information as simple "bundles of facts" and knowledge as more coherent interpretative packages that contextualize, organize and integrate mere facts. In practice, the terms are all too often used loosely and interchangeably.

5 The roles of personal and social motivations, institutional arrangements, the public culture, and technology in fragmenting and constricting the pool of general knowledge are discussed in Ungar $(1999,2000 \mathrm{a})$. The 
focus is on what knowledge is in demand in particular social situations. The popular culture, through a series of pervasive and unavoidable "screens," puts a premium on celebrities, logos, and other icons. This culture is increasingly indifferent to shop, intellectual and ideological talk.

6 Previous research on the concept of cultural literacy employs true-false and/or multiple-choice tests, potentially obscuring the question of what students actually know. That is, students have a reasonable change of guessing correct responses, even when totally ignorant of the subject matter.

7 Given the number of items to compare and the associated problem of statistical independence, the $20 \%$ difference was used to capture substantive significance. In this regard, only four items revealed a $15 \%$ to $19 \%$ difference between genders. In reverse, there were no items for which identification by females was even $10 \%$ higher than by males.

\section{References}

Barley, S., \& Orr, J. (1997). Between craft and science: Technical work in U.S. settings. Ithaca, NY: Cornell University Press.

Barnard, R., Cosgrave, D., \& Welsh, J. (1998). Chips and pop: Decoding the Nexus generation. Toronto, ON: Malcolm Lester Books.

Bart, W., \& Evans-Stout, K. (1997). An investigation of cultural literacy among high school students and prospective high school teachers. Psychological Reports, 76, 1163-1168.

Beniger, J. (1986). The control revolution: Technological and economic origins of the information society. Cambridge, MA: Harvard University Press.

Bercuson, D., Bothwell R., \& Granatstein, J. (1997). Petrified campus: The crisis in Canada's universities. Toronto, ON: Random House.

Bibby, R. (2001). Canada's teens: Today, yesterday and tomorrow. Toronto, ON: Stoddart.

Breivik, P (1998). Student learning in the information age. Phoenix, AZ: Oryx Press.

Coetzee, J. (1999). Disgrace. London: Secker and Warburg. 
Cowen, T. (1998). In praise of commercial culture. Cambridge, MA: Harvard University Press.

Dente, K. (2000). Parents still think tanning is healthy for children. Journal of the American Academy of Dermatology, 42, 13-17.

Dijk, V. (1988). News as discourse. Hillsdale, CA: Lawrence Erlbaum.

Drucker, P. (1993). Post-capitalist society. New York, NY: Harper Collins.

Epstein, S. (1996). Impure science: AIDS, activism and the politics of knowledge. Berkley, CA: University of California Press.

Gabler, N. (1998). Life, the movie: How entertainment conquered reality. New York, NY: Knoph.

Granatstein, J. (1996). Who killed Canadian history? Toronto, ON: Harper Collins.

Hirsch, E. (1987). Cultural literacy: What every American needs to know. Boston, MA: Houghton Mifflin.

Hirsch, E., Kett, J., \& Trefil, J. (1993). The dictionary of cultural literacy. Boston, MA: Houghton Mifflin.

Jones, S. (1993). Up against the wall. New York Review of Books, (October), 33-34.

Keegan, J. (1998). The First World War. Toronto, ON: Random House.

Lane, R. (1966). The decline of politics and ideology in a knowledgeable society. American Sociological Review, 21, 648-661.

Lukasiewicz, J. (1994). The ignorance explosion: Understanding industrial civilization. Ottawa, ON: Carelton University Press.

Martin, W. (1995). The global information society. Hampshire, UK: Ashlib.

Miller, S., \& Goyder, J. (2000). The eroding standards issue: A case study from the University of Waterloo. The Canadian.Journal of Higher Education, 30(3), 57-78.

Owens, B. (2000). Lifting the fog of war. New York, NY: Farrar, Straus, and Giroux.

Paxton, P. (1999). Is social capital declining in the United States: A multiple indicator assessment. American Journal of Sociology, 105, $88-127$. 
Reser, J., \& Smithson, M. (1988-89). When ignorance is adaptive: Not knowing about the nuclear threat. Knowledge in Society, 1, 7-27.

Ross, A. (1994). The new smartness. In G. Bendewr, \& T. Druckery (Eds.), Culture on the brink (pp. 329-333). Seattle, WA: Bay Press.

Royce, J. (1997). Surviving information overload: Lessons from the reading reluctance research. School-Libraries-Worldwide, 3, 39-46.

Ungar, S. (1999). Icons and gumpism: Ignorance in the knowledge society. Paper presented at the meetings of the SSHRC Project on Trends, Ottawa, ON.

Ungar, S. (2000a). Knowledge, ignorance and the popular culture: Climate change versus the ozone hole. Public Understanding of Science, 9, 297-312.

Ungar, S. (2000b). Why climate change is not in the air: Popular culture and the whirlwind effect. In D. Scott (Ed.), Climate change communication: Proceeding of an international conference (pp. A2: 8-14). Hull, QC: Environment Canada.

Viswanath, K., \& Finnegan, J. (1996). The knowledge gap hypothesis: Twenty-five years later. In B. Burleson (Ed.), Communication yearbook, 19 (pp. 187-227). Thousand Oaks, CA: Sage.

Webster, F. (1995). Theories of the information society. London: Routledge.

Wilson, J., \& Gove, W. (1999). The intercohort decline in verbal ability: Does it exist? American Sociological Review, 64, 253-256. 